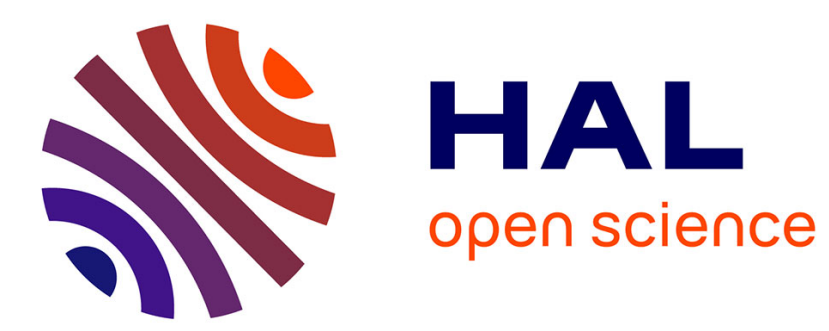

\title{
DEVELOPMENT AND DIAGNOSTICS OF A Z-PINCH PLASMA TARGET
}

\author{
R. Noll, C. Haas, H. Kunze
}

\section{To cite this version:}

R. Noll, C. Haas, H. Kunze. DEVELOPMENT AND DIAGNOSTICS OF A Z-PINCH

PLASMA TARGET. Journal de Physique Colloques, 1988, 49 (C7), pp.C7-177-C7-184. 10.1051/jphyscol:1988720 . jpa-00228204

\section{HAL Id: jpa-00228204 https://hal.science/jpa-00228204}

Submitted on 1 Jan 1988

HAL is a multi-disciplinary open access archive for the deposit and dissemination of scientific research documents, whether they are published or not. The documents may come from teaching and research institutions in France or abroad, or from public or private research centers.
L'archive ouverte pluridisciplinaire HAL, est destinée au dépôt et à la diffusion de documents scientifiques de niveau recherche, publiés ou non, émanant des établissements d'enseignement et de recherche français ou étrangers, des laboratoires publics ou privés. 
JOURNAL DE PHYSIQUE

Colloque C7, supplément au $\mathrm{n}^{\circ} 12$, Tome 49, décembre 1988

\title{
DEVELOPMENT AND DIAGNOSTICS OF A Z-PINCH PLASMA TARGET
}

\author{
R. NOLL, C.R. HAAS* and H. KUNZE \\ Fraunhofer-Institut für lasertechnik, Steinbachstr. 15. \\ D-5100 Aachen, F.R.G. \\ "Lehrstuhl für Lasertechnik, RWTH Aachen, steinbachstr. 15 , \\ D-5100 Aachen, F.R.G.
}

\begin{abstract}
Résumé - Af in de rechercher l'interaction de faiscaux d'ions lourds rapides avec de la matière chaude, un expériment faisceau-plasma est installé dans la région de stripper de I'UNILAC à la GSI, Darmstadt. Les exigences du target ont été déduites de prédictions du ralentissement d'énergie et de l'état de charge ainsi que des propriétés du faisceau d'ions: un plasma hydrogène totalement ionise, une géométrie cylindrique du plasma, électrons/aire $\geqq 10^{19} / \mathrm{cm}^{2}$, durée $\geqq 15 \mathrm{~ns}$. Un z-pinch qui est adaptable à la structure de 1 'accélérateur a été désigné et développé af in d'accomplir ces spécifications du target. on analyse le décharge du z-pinch avec des diagnostiques électriques et optiques. Ces derniers montrent la formation d'un plasma cylindrique uniforme qui est long de $20 \mathrm{~cm}$ et qui a une diametre de $>5 \mathrm{~mm}$.

Abstract - For the investigation of the interaction of fast heavy ion beams with hot matter, a beam-plasma experiment is set-up in the stripper region of the UNILAC at the GSI, Darmstadt. The target requirements are deduced from theoretical predictions of energy loss and charge state as well as from the features of the ion beam: fully ionized hydrogen plasma, cylindrical plasma geometry, electrons/area $\geqq 10^{19} / \mathrm{cm}^{2}$, life time $\geqq 15 \mathrm{~ns}$. A z-pinch device which is adaptable to the accelerator structure, was designed and developed to meet these target specifications. The $z$-pinch discharge is investigated with electrical and optical diagnostics. The latter show that a uniform cyindrical plasma pinch is formed with a length of $20 \mathrm{~cm}$ and a diameter of $>5 \mathrm{~mm}$.
\end{abstract}

\section{Introduction}

The experimental investigation of the interaction processes of fast heavy ion beams with hot matter is of fundamental interest for atomic physics and plasma physics. At the Gesellschaft für Schwerionenforschung (GSI) in Darmstadt, a heavy ion synchrotron (SIS) and a storage ring (ESR) with electron cooling are presently under construction. These facilities will open the possibility to create hot dense plasmas by irradiating small gaseous or solid state targets with intense heavy ion beams. The generated plasmas will be studied with respect to heavy ion inertial fusion and $x-r a y$ laser schemes. Hence the knowledge of experimental data of charge state and energy loss of fast heavy ions in plasmas is an essential basis for the design of future experiments at the SIS/ESR. In a joint project between the GSI in Darmstadt, the Max-Planck-Institut für Quantenoptik in Garching and the Fraunhofer-Institut für Lasertechnik in Aachen, first experimental studies of the interaction of fast heavy ions with hot matter will be performed using an externally generated plasma as a target for the ion beam from the stripper region of the UNILAC.

\section{Plasma Target Requirements}

Theoretical calculations predict significant changes in charge state and stopping power of fast ions in a plasma /1/. In a fully ionized plasma, capture processes of electrons to heavy ion projectiles are dominated by radiative electron capture and dielectronic recombination. The cross sections for these processes are by some orders of magnitude lower than Coulomb capture cross sections for bound electrons. As a consequence, the average charge states of heavy ions in plasmas are significantly greater than those in cold matter. The energy loss of the ions described by the Bethe formula is proportional to the square of the effective charge state of the projectiles. Thus an increased energy loss and a corresponding range shortening is expected in the ion beam-plasma experiment. 
The plasma target has to meet the following requirements:

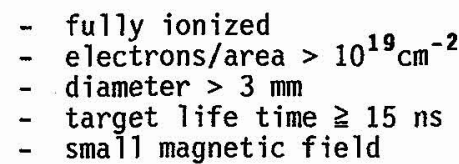

For the projected experiment, an ion beam of Iodine ${ }^{32+}$ with a fixed energy of $1.4 \mathrm{MeV} / \mathrm{u}$ will be available from the UNILAC.

For electron area densities above $10^{19} \mathrm{~cm}^{-2}$, the theoretically predicted charge state of Iodine ${ }^{32+}$ projectiles injected to a hydrogen plasma, is significantly higher than that for a cold hydrogen target $/ 1 /$. The requirement for the diameter is a consequence of the ion beam spot size. The plasma life time should be greater than the transit time of the interacting projectiles traversing the target. A small magnetic field inside the plasma reduces disturbing ion beam deflections.

Several different plasma sources have been considered as possible targets. A z-pinch device is the most favourable candidate due to its plasma parameters, which are compatible to the above requirements, and its geometrical adaptability to the beam line structure. Fig.1 shows schematically the set-up of the beam-plasma experiment with a z-pinch.

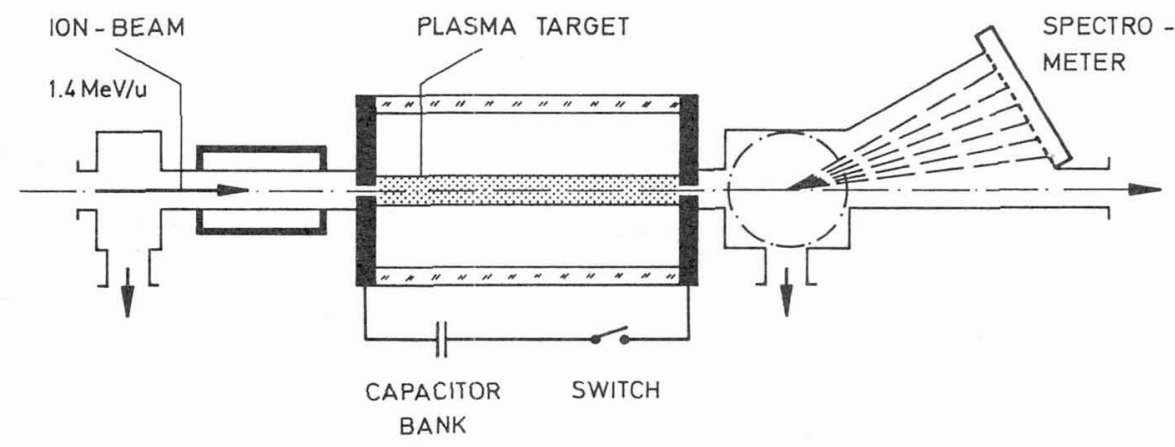

Fig. 1: Set-up of the beam-plasma experiment with a z-pinch and diagnostics.

The ion beam is injected coaxially into a cylindrical plasma. The charge state and energy loss behind the interaction region are measured with a spectrometer and time of flight systems. The ions propagate via windowless entrance and exit apertures in order to avoid changes in the charge state distribution, which cannot be discriminated from the one induced by the plasma. The pressure gradients between beam line and discharge region are maintained by differential pumping.

In a z-pinch device a plasma is generated using a fast electrical discharge in a cylindrical glass tube with a low pressure gas filling. A capacitor bank of low inductance is switched to the electrodes at the ends of the discharge vessel. The plasma is ignited near the inner wall of the glass cylinder. The capacitors feed a fast rising current of typically $10^{12} \mathrm{~A} / \mathrm{s}$ into the plasma load. The azimuthal field of the axial current flow inside the plasma compresses the hollow plasma sheath towards the axis. At the end of the radial collapse, a plasma cylinder is formed on the axis.

\section{Design of the $z-p$ inch device}

A modified z-pinch was designed as a plasma target which is adaptable to the beam line structure in space and time. Capacitor bank, stripline, switch and discharge vessel of the z-pinch (cf. Fig. 1, Fig. 4) are arranged to get a compact device geometry and an optically free axis for the access of the beam 1 ine and the optical diagnostics. A triggerable switch is used to synchronize the plasma formation to the temporal structure of the ion beam. 
Further design criteria are:

a) Ignition of the plasma near the inner wall of the glass cylinder via a sliding discharge in order to create a homogeneous plasma sheath.

The ignition phase determines the reproducibility and symmetry of the hydrodynamics of a $z$-pinch discharge $12 /$. To favour a sliding discharge, the electrodes are shaped to generate a suitable electrical field distribution (cf. Fig. 5). Electrons emitted by a knife edge inserted in the cathode close to the inner wall, are accelerated to the glass surface where they release secondary electrons. The electrons are multiplied and their mean kinetic energy is reduced to an energy range, where the cross section for collisional ionization of hydrogen attains a maximum. The sliding discharge evolves forming a homogeneous plasma sheath.

b) Pinch time at current zero passage in order to minimize magnetic fields.

The behaviour of a pulsed plasma discharge is similar to the one of an LC-oscillator with a time varying plasma impedance. Conventional operation of z-pinches is characterized by a maximum of the electrical current during the phase of pinch formation. The resulting strong magnetic fields close to the pinch lead to deflections of the ion projectiles and, consequently, may disturb the beam-plasma experiment. In contrast to this, the idea is to tune the parameters of the discharge circuit (e.g. voltage, gas filling pressure, geometry), so that a zero passage of the oscillating discharge current coincides with the pinch time of the plasma on the axis. This would be a suitable interaction time for the ion beam with the plasma pinch.

c) Approximately acceleration free collapse to reduce the growth rate of Rayleigh-Taylor instabilities.

The plasma geometry can be affected by Rayleigh-Taylor instabilities (RTI) during the collapse phase $13 \%$. The growth rate of the RTI is proportional to the square root of the acceleration of the interface between the plasma and the magnetic piston. Model calculations (see below) show that there exists a parameter regime for the z-pinch device where the collapse is approximately free of acceleration.

d) Optimum shock velocity to obtain high electron densities.

The typical radial collapse velocities amount about $6 \cdot 10^{6} \mathrm{~cm} / \mathrm{s}$ (cf. Fig. 3) corresponding to a supersonic motion in hydrogen gas with a Mach number of 50 . Hence a shock wave evolves in front of the magnetic piston. Fig. 2 shows the compression density ratio $\rho_{2} / \rho_{1}$ across the shock, the degree of ionization and the electron density as a function of the shock velocity $/ 4 /$. For shock velocities greater than $v_{t h}=6.10^{6} \mathrm{~cm} / \mathrm{s}$ hydrogen gas is fully ionized. The velocity $v_{t h}$ satisfies an energy matching condition. At $v_{t h}$ the kinetic energy of a hydrogen molecule is equal to the sum of dissociation and ionizaton energy of $H_{2}$. Fig. 2 shows that at the shock velocity $v_{t h}$ ' the electron density behind the compression shock attains a maximum. Hence for an optimum shock velocity $v$ - with respect to high electron densities in a fully ionized plasma - holds $v \geqq v_{t h}$.

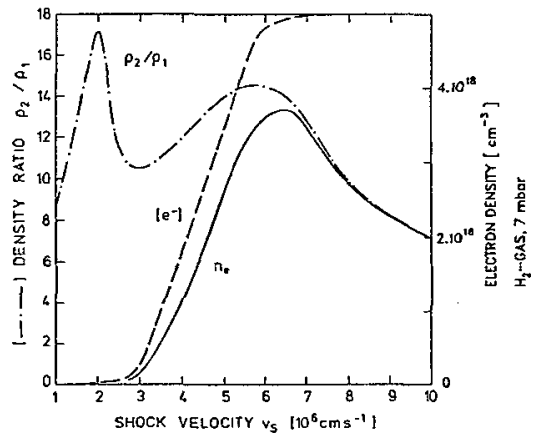

Fig. 2: Density ratio across the shock, degree of ionization and electron density as a function of the shock velocity. 
For the design of the z-pinch - especially concerning items b), c) and d) - the discharge dynamics is simulated with the help. of the snow plow model $/ 5 /$. The model includes the hydrodynamic equation of motion and the circuit equation. As a result of the magnetic pressure force, the current shell formed after ignition near the inner wall of the glass tube accelerates inwards. It is assumed that this piston sweeps up and captures all particles it encounters on its propagation to the axis. Input parameters of the model are the z-pinch geometry, the electrical data of the discharge circuit and the gas filling pressure of the glass vessel.

The coupled differential equations of the model are integrated numerically obtaining the radial position $r_{p}$ of the plasma sheath and the plasma current $I_{p}$ as a function of time. Fig. 3 shows a solution, which fits the design criteria b), c) and d).
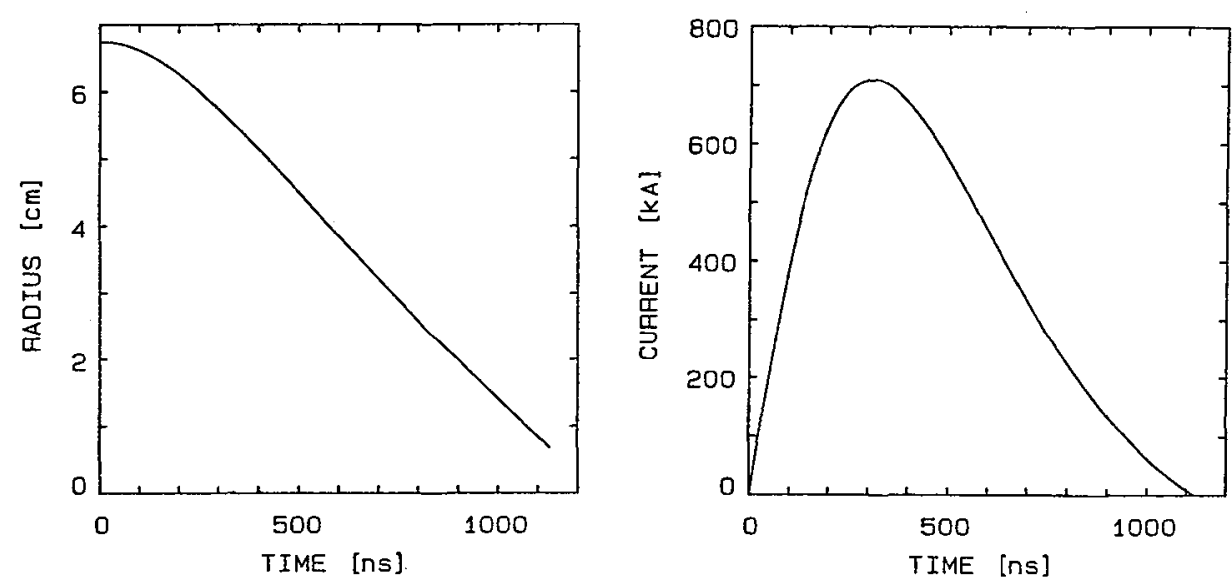

Fig. 3: Radial position of the plasma sheath and plasma current as a function of time calculated with the snow plow model (parameters: capacity $4 \mu \mathrm{F}$, charging voltage $65 \mathrm{kV}$, start radius $6.7 \mathrm{~cm}$, plasma length $20 \mathrm{~cm}$, hydrogen filling pressure 7 mbar, short circuit inductance $10 \mathrm{nH}$ ).

\section{Construction and development of the z-pinch}

The projected parameters of the z-pinch device listed in Table 1, were based on the snow plow calculations.

Table 1: Parameters of the z-pinch device

$\begin{array}{lr}\text { bank energy } & 1-10 \mathrm{~kJ} \\ \text { bank voltage } & 20-70 \mathrm{kV} \\ \text { bank capacitance } & 4 \mathrm{\mu F} \\ \text { bank inductance } & 15 \mathrm{nH} \\ \text { current rise } & \leqq 5 \cdot 10^{12} \mathrm{~A} / \mathrm{s} \\ \text { max. current } & \leqq 8 \cdot 10^{5} \mathrm{~A} \\ \text { filiing pressure } \mathrm{H}_{2} 1-10 \mathrm{mbar} \\ \text { length } \\ \text { radius }\end{array}$

In Fig. 4 the set-up of the z-pinch device is shown schematically. A critical component is the switch which has to operate at electrical powers of up to $100 \mathrm{GW}$. Additionally, the switch should be triggerable to synchronize the plasma formation to the temporal structure of the ion beam. The specifications for the hold-off voltage, the peak current and the switch inductivity are a consequence of the required z-pinch parameters (cf. Table 1, $70 \mathrm{kV}, 800 \mathrm{kA},<10 \mathrm{nH}, \mathrm{re-}$ spectively). 

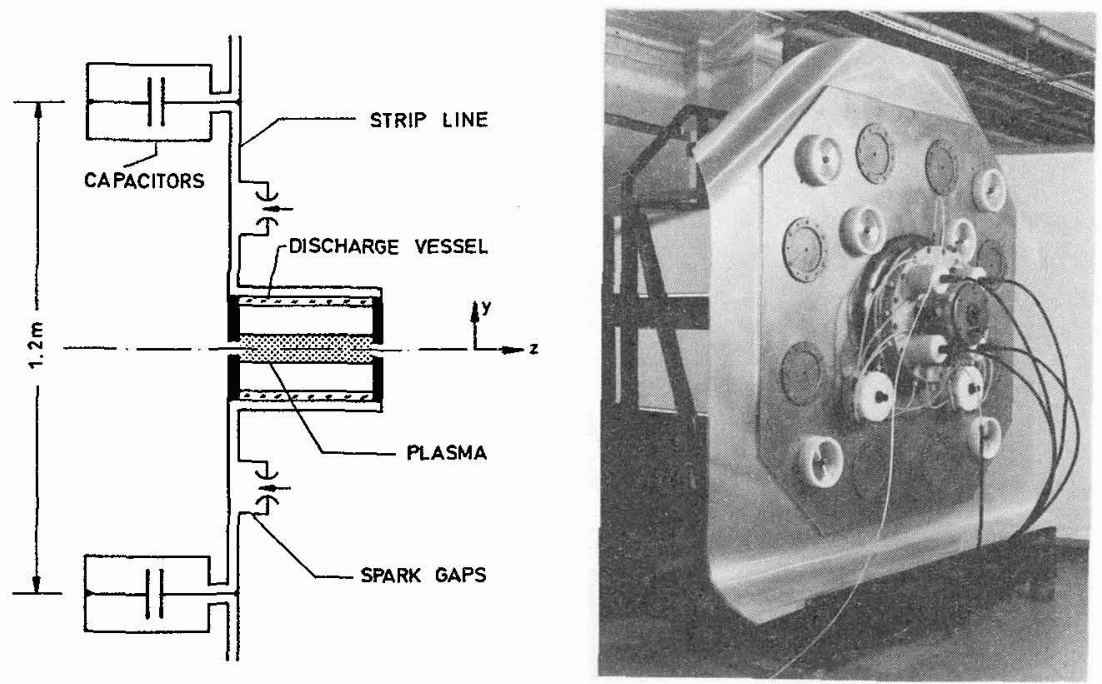

Fig. 4: Schematical set-up and photograph of the z-pinch device.

We have designed and constructed a multichanne] spark gap switch which is triggered using the field distortion method. Fig. 5 shows a sectional view of the switch and the discharge vessel.

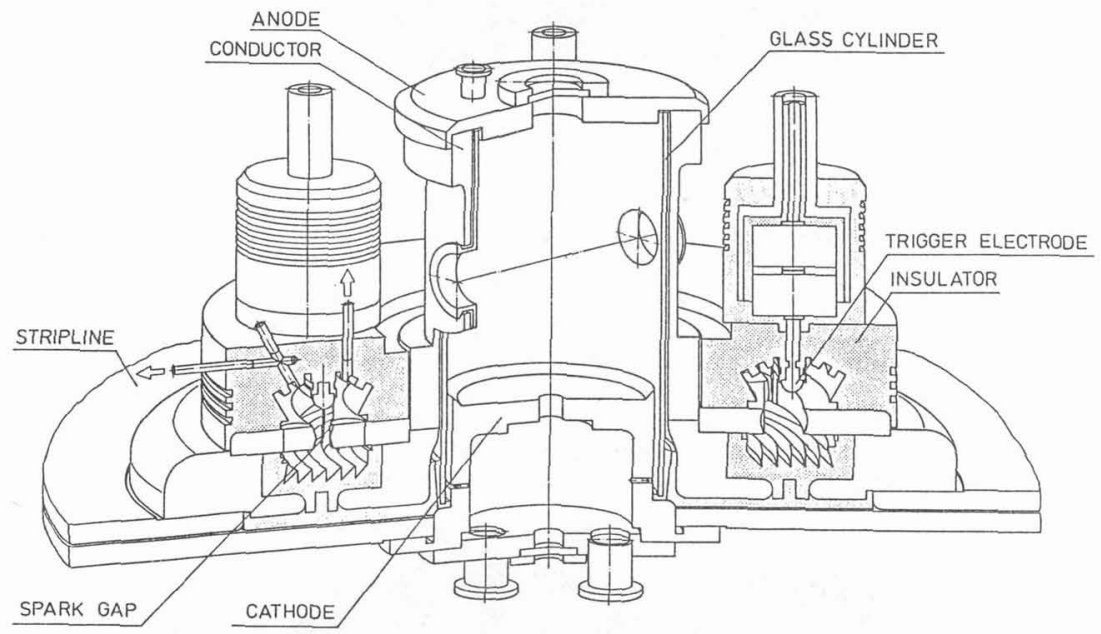

Fig. 5: Sectional view of the multichannel spark gap switch and the discharge geometry. For the optical diagnostics of the plasma, the outer conductor either has two observation apertures or is constructed from a perforated metal plate.

Low inductance and switch arrangement close to the load, $i$. e. the discharge volume, enables a steep current rise of up to $10^{13} \mathrm{~A} / \mathrm{s}$, which is necessary for a homogenous plasma ignition. The switch incorporates eight electrically and optically coupled spark gaps, which are symmetrically arranged on the circumference of the load. A high voltage pulse at the trigger electrodes with a voltage rise of $>40 \mathrm{kV} / \mathrm{ns}$ ignites the spark gaps. Parallel operation of the eight spark gaps is necessary for a symmetric current flow to the discharge vessel. The light emission of the sparks is observed via fiber optics and a streak camera to control the switch symmetry.

The switch diagnostics is used to optimize the operation parameters: gas pressure in the switch, trigger pulse etc. The measured short circuit inductance of the switch is $7.5 \mathrm{nH}$, which is sufficently small.

An insulation system was developed for the transition region between the bushings of the capacitors and the strip line geometry, which has been applied for a patent. 


\section{Diagnostics of the plasma target}

The visible plasma emission is used to diagnose the discharge dynamics. The collapse and pinch phase is observed with a streak camera, where the slit is aligned perpendicular to the axis of symmetry ( $i$. e. the z-axis in Fig. 4). Fig. 6 shows the corresponding streak image. The plasma sheath starts at a radius of about $7 \mathrm{~cm}$ and collapses to the center, forming a pinched plasma column. Depending on the discharge parameters (e.g. filling pressure, bank voltage), the typical collapse velocities range from $10^{6} \mathrm{~cm} / \mathrm{s}$ to $10^{7} \mathrm{~cm} / \mathrm{s}$. The observed collapse is nearly free of acceleration. Consequently, the growth rates of disturbing Rayleigh-Taylor instabilities can be kept small. The pinched plasma exists for more than 100 ns, which is significantly greater than the transit time of the ion projectiles $(1.5 \mathrm{MeV} / \mathrm{u})$. Additionally, several ion bunches can interact during the plasma lifetime, because their mutual temporal separation amounts $37 \mathrm{~ns}$.

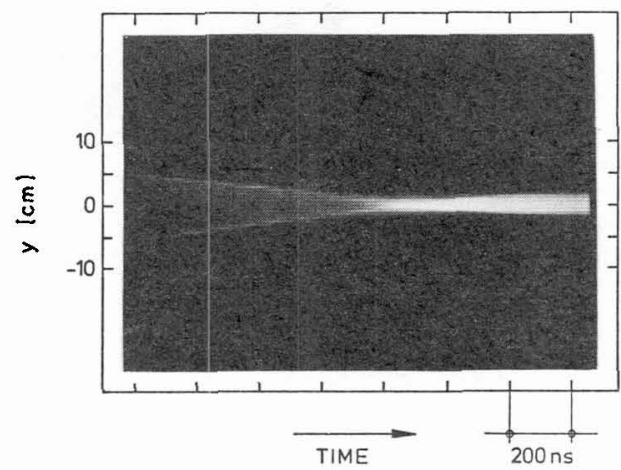

Fig. 6: Streak image of the collapsing z-pinch plasma (parameters: $U=35 \mathrm{kV}, \mathrm{p}_{\mathrm{H} 2}=.3 \mathrm{mbar}$ ).

The geometry of the z-pinch plasma is observed with an image converter camera. The exposure time is 15 ns to avoid motional blurring caused by the fast plasma dynamics. Fig. 7 shows an image of the pinched plasma. A uniform plasma cylinder is observed which has a diameter of $1 \mathrm{~cm}$ and a length of $20 \mathrm{~cm}$. Since the diameter of the injected ion beam will be $3 \mathrm{~mm}$, it can be expected that the propagation volume of the ions is completely enclosed by the plasma target. The reproducibility of pinch formation and geometry in terms of the standard deviations of normalized pinch times and radi $i$, amounts about $5 \%$.

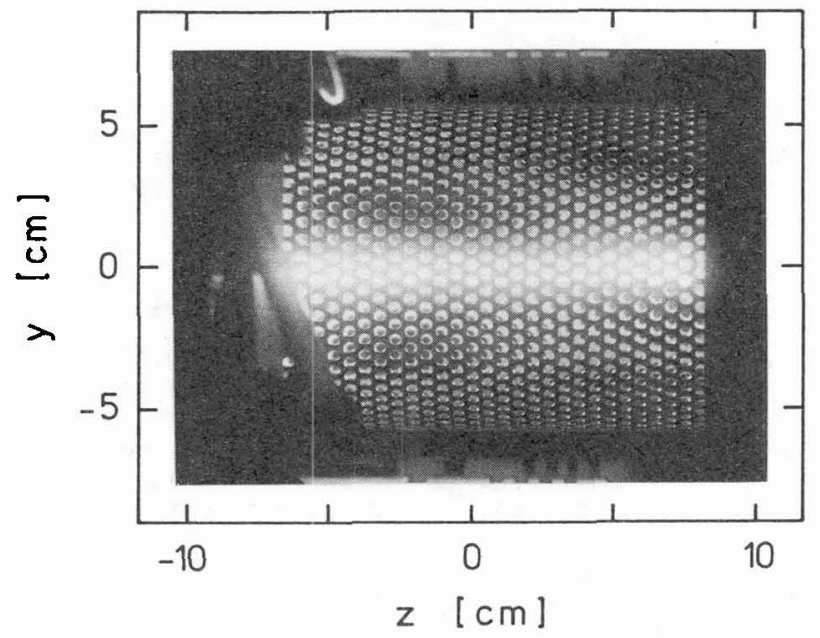

Fig. 7: Pinched plasma recorded with an image converter camera (parameters: $\mathrm{U}=35 \mathrm{kV}$, $p_{\mathrm{H} 2}=1$ mbar). A perforated outer conductor is used for observation (cf. Fig. 5). 
In Fig. 8, the velocity of the radial collapsing magnetic piston is shown as a function of the charging voltage of the capacitor bank. Parameter is the hydrogen filling pressure. The velocities are measured with a streak camera. The experimental data of Fig. 8 can be described by a power law: $v \propto U^{1.9}$. For charging voltages of about $U=35 \mathrm{kV}$ the measured velocity exceeds the threshold $v_{t h}$ (cf. chapter 3 ) for an ionizing shock wave.

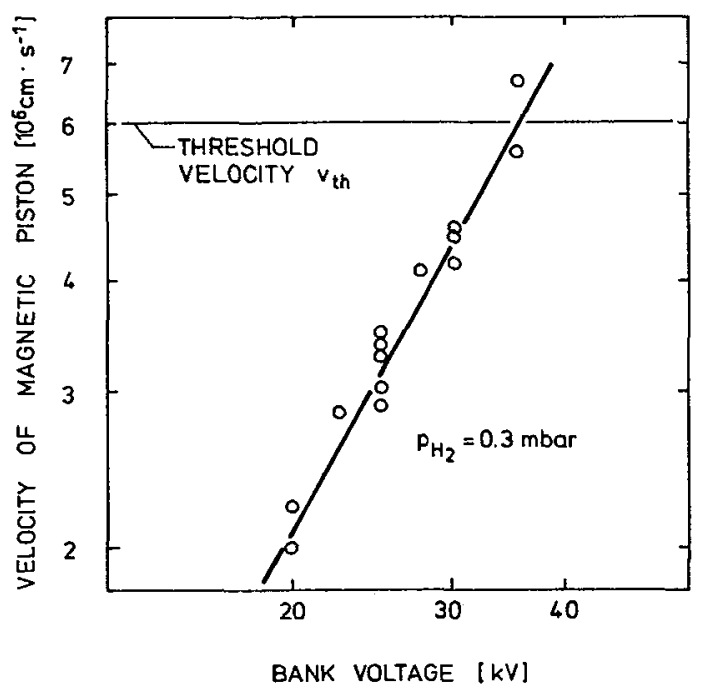

Fig. 8: Velocity of the magnetic piston as a function of the bank voltage. For velocities greater than $v_{t h}$, a fully ionized hydrogen plasma is created by strong shock waves.

The line of sight electron density along the trajectory of the ion beam will be measured using Mach-Zehnder interferometry where the fringe displacement is directly related to the number of electrons per area. In the projected interferometric set-up, the fringes will be observed with a streak camera to determine the time dependent electron density at the interaction time of the ion bunch with the plasma. This diagnostic is presently under construction. First measurements of the electron density were performed with holographic interferometry in transverse direction (i.e. the $y$-axis in Fig. 4) $/ 6 /$. The optical set-up is shown in Fig. 9. The light source is a commercial ruby laser (JK, HLS 2) operated in Q-switch mode. The FWHM time of the Q-switch pulses amounts about 20 ns. The laser pulses were shortened externally to about $5 \mathrm{~ns}$, using a gas breakdown in the focus of the first lens (cf. Fig. 9).

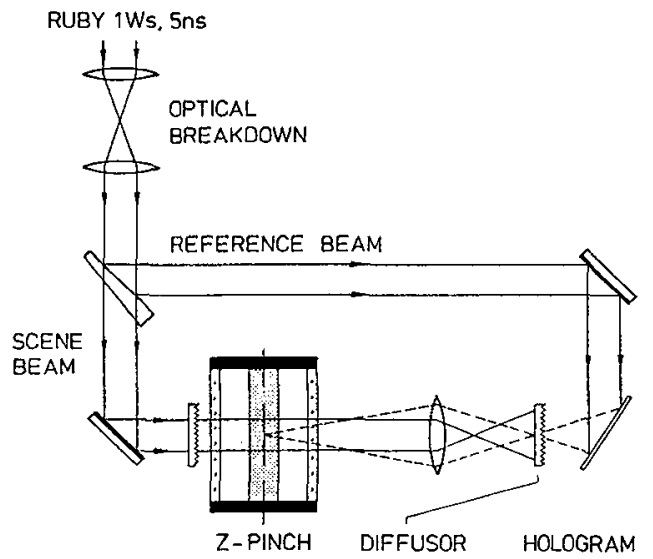

Fig. 9: Optical set-up for the holographic interferometry of the z-pinch plasma. 
The diffusing screens in the object beam were used to homogenize the illumination of the plasma and the hologram. The plasma midplane is imaged onto the second diffusing screen to reduce the effects of the density gradients of the object which would otherwise result in a shadowgraph instead of an interferogram of the plasma. Fig. 10 shows a reconstructed interferogram recorded at the pinch time. Two adjacent dark fringes correspond to a change of $3.210^{17}$ electrons $/ \mathrm{cm}^{2}$. Due to the fast dynamics of the plasma, the fringes in the central region of the pinch cannot be resolved. From Fig. 10, a lower limit for the electron density was estimated: $n_{e}>10^{18} \mathrm{~cm}^{-3}$, which corresponds to an extrapolated electron area density in the axial direction of $>2 \cdot 10^{19} \mathrm{~cm}^{-2}$ (length of the plasma $20 \mathrm{~cm}$ ).

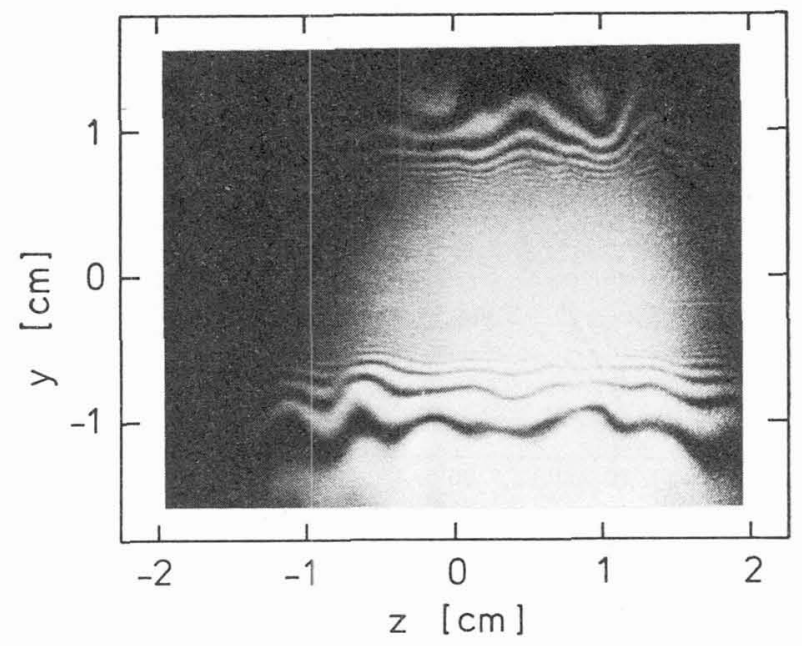

Fig. 10: Interferogram of the $\mathrm{z}$-pinch (parameters: $\mathrm{U}=37.5 \mathrm{kV}, \mathrm{P}_{\mathrm{H} 2}=1 \mathrm{mbar}$ ).

Table 2 summarizes the requirements for the plasma target and the first experimental results of the diagnostics at the z-pinch system.

Table 2: Requirements for the plasma target and first experimental results.

\begin{tabular}{|l|l|l|}
\hline & requirements & experiment \\
\hline target state & fully ionized & $v>v_{\text {th }}$, ionizing shock wave \\
plasma geometry & length $20 \mathrm{~cm}$ & $20 \mathrm{~cm}$ \\
& diameter $>3 \mathrm{~mm}$ & $>5 \mathrm{~mm}$ \\
pinch duration & $>15 \mathrm{~ns}$ & $>100 \mathrm{~ns}$ \\
magnetic field & $<.1 \mathrm{~T}$ & pinch at current zero \\
reproducibility & $-\overline{10^{19}} \mathrm{~cm}^{-2}$ & $>5 \%$ \\
electrons/area & $>10^{19} \mathrm{~cm}^{-2}$ \\
\hline
\end{tabular}

References

11/ T. Peter, Diplom thesis, MPQ 105, 1985

12/ H. Krompholz, W. Neff, F. Rühl, K. Schönbach, G. Herziger

Phys. Lett. 77A(1980)246

13/ C. R. Haas, R. Noll, F. Rühl, G. Herziger

14/ R. A. Gross

Rev. of Mod. Phys. 37(1965)724

15/ N. A. Kral1, A. W. Trivelpiece Principles of Plasma Physics

Mc Graw-Hill, N. Y., 1973

16/ R. F. Gribble, W. E. Quinn, R. E. Siemon

Phys. Fluids 14(1971)2042 